\section{Somatotrophs and lactotrophs: an immunohistochemical study of Gallus domesticus pituitary gland at different stages of induced moult}

\author{
M.A. Sandhu, ${ }^{1}$ Z.U. Rahman, ${ }^{2}$ A. Riaz, ${ }^{1}$ \\ S.U. Rahman, ${ }^{3}$ I. Javed, ${ }^{2}$ N. Ullah ${ }^{1}$ \\ 'Department of Physiology, PMAS, \\ Arid Agriculture University, Rawalpindi, \\ Pakistan; \\ 2Department of Physiology and \\ Pharmacology, University of Agriculture, \\ Faisalabad, Pakistan; \\ ${ }^{3}$ Department of Microbiology, University \\ of Agriculture, Faisalabad, Pakistan
}

\section{Abstract}

The objective of this study was to determine the distribution of somatotrophs and lactotrophs and conduct a morphometrical analysis of immunoreactive somatotrophs and lactotrophs in the pituitary glands of White Leghorn Hens (Gallus domesticus) during the period of induced moult. We divided the periods of induced moulting into three phases viz. 7, 14 and 21 days. The labeled alkalinephsphatase method with anti-GH (growth hormone) and anti-PRL (prolactin) as a primary antibody was used to detect somatotrophs and lactotrophs, in the midsagital sections of chicken adenohypophysis. Immunohistochemistry showed that somatotrophs are not only confined to the cephalo-caudal axis but can also be found in the caudal lobe; while lactotrophs were distributed in both lobes of the anterior pituitary gland at all stages of moulting (7, 14 and 21 days). Lactotrophs were of different shapes but somatotrophs were oval to round in morphology. At the given stages of induced moulting, some hypertrophied lactotrophs were also present after 7 days of induced moult in the anterior pituitary gland. However, there were moulting-related changes: from 7 to 21 days of induced moulting the immunoreactive-PRL cell population decreased, while the mean lactotroph size was more than that of somatotrophs. Basic quantitative and morphological information relating to somatotrophs and lactotrophs during the period of induced moult in laying hens is reported here and the changes brought about by induced moulting are restricted to PRL positive cells rather than $\mathrm{GH}$ positive cells.

\section{Introduction}

Five major types of hormone secreting cells are present in the avian and mammalian anterior pituitary. The avian adenohypophysis is different from mammals as it consists of two distinct lobes, i.e. cephalic and caudal lobes; ${ }^{1}$ the intermediate lobe as well is absent. Somatotrophs and lactotrophs belong to the acidophilic classification of cells and have phenotypic plasticity that also alters the hormonal profiles of Gallus domesticus according to the physiological state of the animal. ${ }^{2}$ In birds, somatotrophs are largely restricted to the caudal lobe; while lactotrophs are found only in the cephalic lobe at most ages, but invade the caudal lobe during the incubation period. Recent studies have shown that lactotrophs and somatotrophs may be co-localized during the incubation state in birds. Increased prolactin levels during the incubation period stimulate FSH and LH secretions. ${ }^{3}$ The staining affinity of lactotroph increases with their hypertrophy as well as during pregnancy and lactation. ${ }^{4}$ Proudman et al. ${ }^{5}$ demonstrated that prolactin-containing cells are active but rare in birds. Induced moulting is an effective tool to improve the overall egg quality and production with the start of incubation behaviour in laying hens. ${ }^{6}$ Moulting induces massive increases in circulating levels of corticosterone and thyroid hormone, ${ }^{7}$ whereas concentrations of estrogen, progesterone and luteinizing hormone (LH) decrease. ${ }^{8}$ These massive changes in the functions of the pituitary gland suggest that it plays a central role in the controlling mechanism of many endocrine functions in the moulting phase of spent layers. The findings of Porter et al..$^{9}$ suggest that the increased number of lactotrophs may be integral to sustaining the elevate levels of prolactin, to support incubation behaviour in birds. Therefore, we undertook a project to determine the changes and correlation between ir-GH (immunoreactive growth hormone), ir-PRL (immunoreactive prolactin) cells, with gradual increase in moulting stress among commercial laying hens.

\section{Materials and Methods}

\section{Animals and experimental design}

A flock of 100 , seventy-week-old Single Comb White Leghorn hens (Gallus domesticus) at the end of first production cycle, were procured from a commercial farm and delivered to the Department of Physiology and Pharmacology, University of Agriculture,
Correspondence: Mansur A. Sandhu, Assistant Professor, Department of Physiology, PMAS, Arid Agriculture University, Rawalpindi, Pakistan.

E-mail: mansoorsandhu@uaar.edu.pk

Key words: Moult, pituitary gland, somatotrophs, lactotrophs, chicken

Acknowledgements: the authors are grateful to Dr. Parlow, NIH, USA for providing the anti-sera and to the Pakistan Science Foundation for the grant to conduct the work.

Received for publication: 17 December 2009. Accepted for publication: 16 April 2010.

This work is licensed under a Creative Commons Attribution 3.0 License (by-nc 3.0).

(c) Copyright M.A. Sandhu et al., 2010

Licensee PAGEPress, Italy

European Journal of Histochemistry 2010; 54:e25 doi:10.4081/ejh.2010.e25

Faisalabad, Pakistan. Upon arrival, the birds were weighed, grouped and acclimated for a week. At the beginning of second week, the hens were subjected to induced moulting by supplementation of $\mathrm{ZnO}$ at the rate of $3 \mathrm{~g} / \mathrm{Kg}^{10}$ feed, with a ligh/dark period of $12 \mathrm{hL}: 16 \mathrm{hD}$ (hL-hour light and hD-hour dark). Throughout the experimental period, the birds had free access to water through nipple drinkers. Sampling was carried out after the cervical dislocation of five randomly selected birds before induced moult (BM); at the end of the first week of moulting; again after fourteen days and then at the end of the moulting period (21 days). The experimental schedule is given in Table 1. All animal procedures were conducted in compliance with protocols approved by the University of Faisalabad Institutional Animal Care and Use Committee.

\section{Serum corticosterone concentrations}

Before decapitation of birds, $5 \mathrm{~mL}$ of blood was removed by cardiac puncture in test tubes and serum was isolated, stored at $-20^{\circ} \mathrm{C}$ till serum corticosterone analysis by ELISA using a kit (DRG Diagnostics, Marburg, Germany. Ref. No. EIA-1887).

\section{Removal of pituitary glands}

After blood collection the pituitary glands were removed by cervical dislocation and preserved in Bouin-Hollande Sublimate for 24 hours. After 24 hours the pituitary glands were dehydrated with an ethanol series, xylene and embedded in paraffin. 


\section{Immunohistochemistry}

A set of serial sections at midsagital plane were cut at $4 \mu \mathrm{m}$ thickness, with adjacent sets separated by at least $40 \mu \mathrm{m}$ and immunostained to locate ir-PRL and ir-GH cells. Individual sections were mounted on Poly Lornithine coated glass slides (Sigma, St Louis, M0, USA). Antigen retrieval is a technique used to normalize staining across the whole section, thereby enabling the proper quantification after immunohistochemistry. TRIS-HCl (0.1 M, pH 6.6) was used as the antigen retrieval buffer with $121^{\circ} \mathrm{C}$ for 10 min with optimal results for single-labelled immunostaining of PRL and GH. Thereafter, immunostaining began with the rehydration of the tissues in TRIS buffer. These tissues were processed for immunohistochemistry after incubation in a solution of $0.3 \% \mathrm{H}_{2} \mathrm{O}_{2}$ in methanol for 30 min to quench the activity of endogenous peroxidase. Subsequently, nonspecific binding was blocked by incubation with normal goat serum (30 min at room temperature). All sections were incubated for 120 min at $37^{\circ} \mathrm{C}$ with rabbit anti-natural human GH antibodies (dilution, 1:5000; courtesy of Dr. Parlow, NIH, USA. NIDDK-anti-hGH-IC-3) in a humidity chamber to prevent drying. After 120 min, the sections were washed thoroughly with TRIS buffer saline (TBS; pH 7.4; 5 min, 3 times) and incubated with biotinylated goat anti-rabbit IgG (KPL, product code 71-00-30) for $30 \mathrm{~min}$. After washing (TBS; $5 \mathrm{~min}, 3$ times), the sections were again incubated for 30 min with a complex of strepavidine-phosphatase (KPL, product code 71-00-45). To visualize the immunoreaction, the sections were incubated with Histomark red solution (KPL, product code 55-69-00). The same procedure was repeated for ir-PRL detection on next section of the same pituitary gland. The sections were incubated with rabbit anti-prolactin antibodies (dilution, 1:1000; courtesy provided by Dr. Parlow NIH, USA. NIDDK-anti-oPRL-IC-1), for 180 min at room temperature in a humidified chamber. All steps for ir-PRL cells immuno-staining were conducted at room temperature.

\section{Specificity and cellular localization of immuno-staining}

To assess the specificity of the NIDDK polyclonal antibodies, we conducted additional control procedures. These trials included omission of primary antibodies or the replacement of primary antibodies with $10 \%$ normal goat serum, or incubations with primary antibodies followed by secondary antibodies produced in an inappropriate host species. There was no immuno-reactivity seen by these control procedures.
Table 1. Experimental design and treatment schedule for zinc induced moult.

\begin{tabular}{lcccc} 
Stage of moult & Weeks of age & Feed, g/bird & Water & Light hours \\
Pre-moult* & WLHSC $^{\circ}$ (sampling) & 120 & Ad libitum & 24 \\
Moulting & $71-73$ (Sampling) & 35 (ZnO 3 g/kg spiked feed) & -do- & 12 \\
\hline Rest Period & $74-75$ & 50 (Ground Corn) & -do- & 12 \\
& $76^{\sharp}$ & 75 (Ground Corn) & -do- & 14 \\
& & $+2 \% \mathrm{CaCO}_{3}$ & & \\
Post-moult & 77 to onward & 120 & -do- & 16 \\
\hline
\end{tabular}

*Deworming, EDS \& ND Vaccination; ${ }^{\circ}$ WLHSC, White Leghorn Single Comb laying hens (Gallus domesticus); \#Start of Egg Production
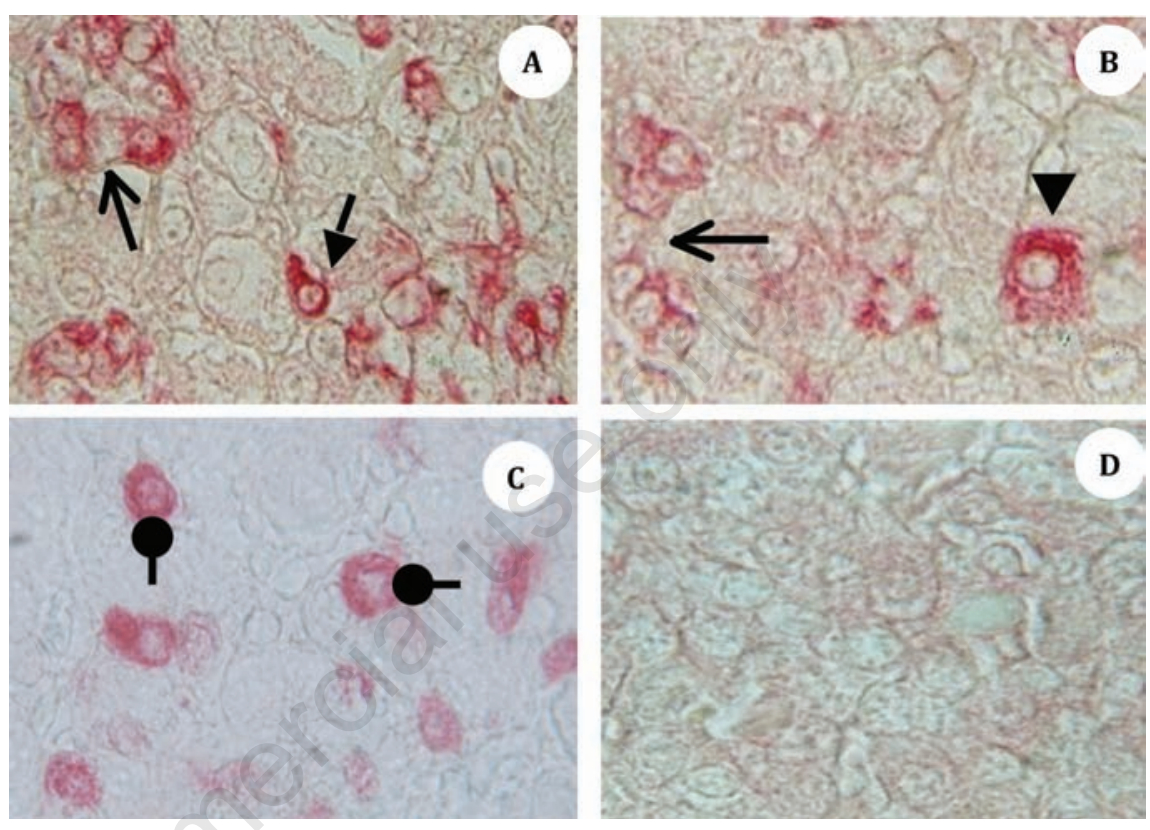

Figure 1. A-D; Photomicrographs (X-1000) of midsagittal sections of pars distalis of moulting White Leghorn Hen (Gallus domesticus) showing (A) cephalic zone of pars distalis, ir-PRL cells (red), small arrow showing an individual ir-PRL cell with cytoplasmic extension and open head arrow is showing a islets of ir-PRL cells. Panel (B) is showing a hypertrophied cell indicated by the arrowhead; note three times bigger cell and open head arrow showing ir-PRL cells islet in crescent shape. (C) Photomicrograph of caudal lobe; roundhead arrows show ir-GH cells, noteworthy that all the cells are oval-to-round shaped with central nucleus. (D) Negative control photomicrograph.

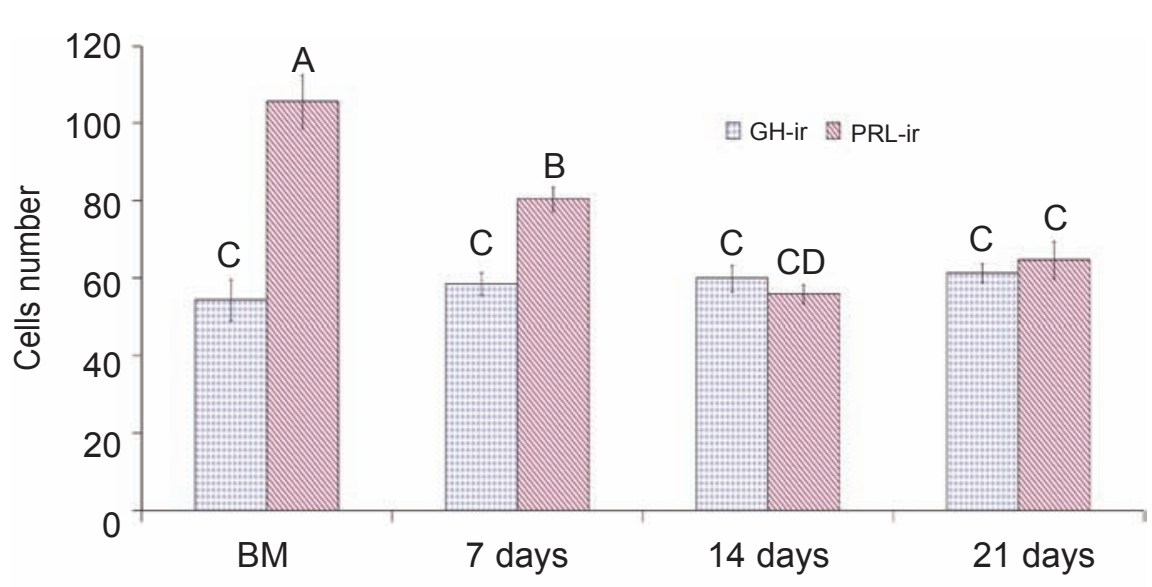

Figure 2. Immunoreactive somatotrophs and lactotrophs population at different stages of zinc induced moulting.GH-ir: growth hormone immunoreactive cells. PRL-ir: prolactin immunoreactive cells $\mathrm{A}-\mathrm{D}=$ do not differ significantly at $\mathrm{P} \leq \mathbf{0 . 0 5}$. 


\section{Quantification of ir-GH and ir-PRL cells}

After immunostaining, the sections were dehydrated and mounted with dibutyl phthalate in xylene (DPX). The numbers of ir-PRL and ir-GH showing a complete cross section of cells with a clear nucleus were counted under a light microscope at X-1000 in midsagittal sections of the moulting hen pituitary gland. Extensive quantification (more than 10,000 cells per treatment) of these pituitaries at the caudal lobe, cephalic lobe and the junction between the two was carried out. The numbers of ir-GH and/or PRL were counted from six midsagittal sections and summed for each hen. Morphometric analyses were carried out in a computer based AutoCAD program (AutoCAD, 2004).

\section{Statistical analysis}

Somatotrophs and lactotrophs were defined as pituitary cells immunopositive for $\mathrm{GH}$ and PRL, respectively. Analysis was performed on the total number of birds within each group expressing the two hormones. The group proportion of pituitary cells expressing $\mathrm{GH}$ and PRL were calculated. All data was presented as mean ( $n=5$ per group) \pm SE. Immunorective cell counts, cell size and corticosterone concentrations among groups were analyzed using the General Linear Models procedure of SAS, Version 6. ${ }^{11}$ The Duncan's multiple range test was used in case of a significant interaction among groups. Differences were considered statistically significant at P-values less than 0.05 .

\section{Results}

Upon necropsy, egg-laying hens were found to have functional ovaries bearing a normal hierarchy of pre-ovulatory follicles, whereas the moulting hens (at 14 days) started decreasing the ovarian clutch and finally maximum regression was observed at 21 days after $\mathrm{ZnO}$ supplemented diet. The immunohistochemistry provided clear and specific staining of GH and PRL cells. Immunoreactions against GH and PRL were localized to the cytoplasm of specific pituitary cells (Figure 1). Omission of primary antibodies or the use of inappropriate host raised secondary antibodies did not produce any immuno-stain. The distributions of ir-PRL and ir-GH cells within pars distalis were identical to some of the previous studies with some differences. It has already been reported that ir-PRL cells are present only in the cephalic lobe of laying hens, but herein we also found ir-PRL cells in the caudal lobe as well as the cephalic lobe of moulting hens. PRL-ir cells were mostly present

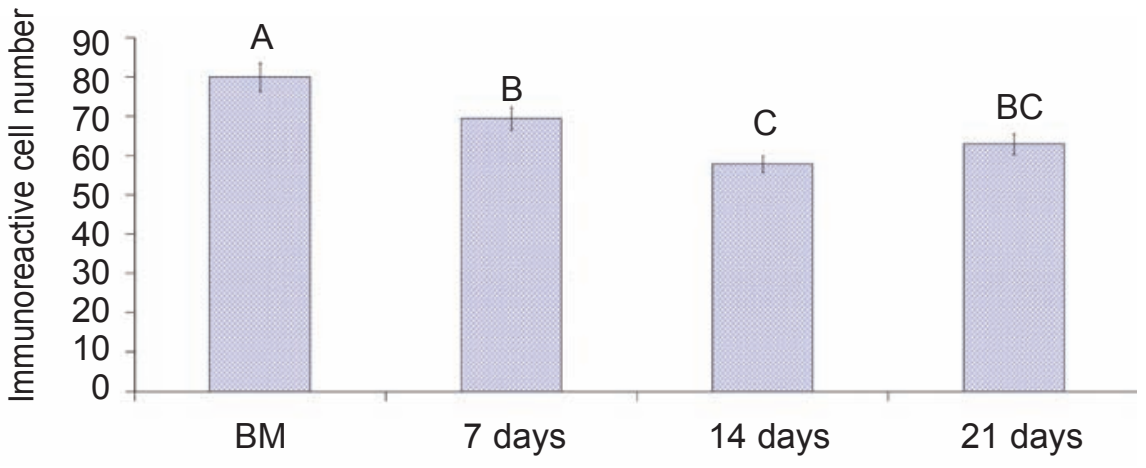

Figure 3. Overall immunoreactive cellular population irrespective of cell type at different stages of zinc induced moult. $A-C=$ do not differ significantly at $P \leq 0.05$.

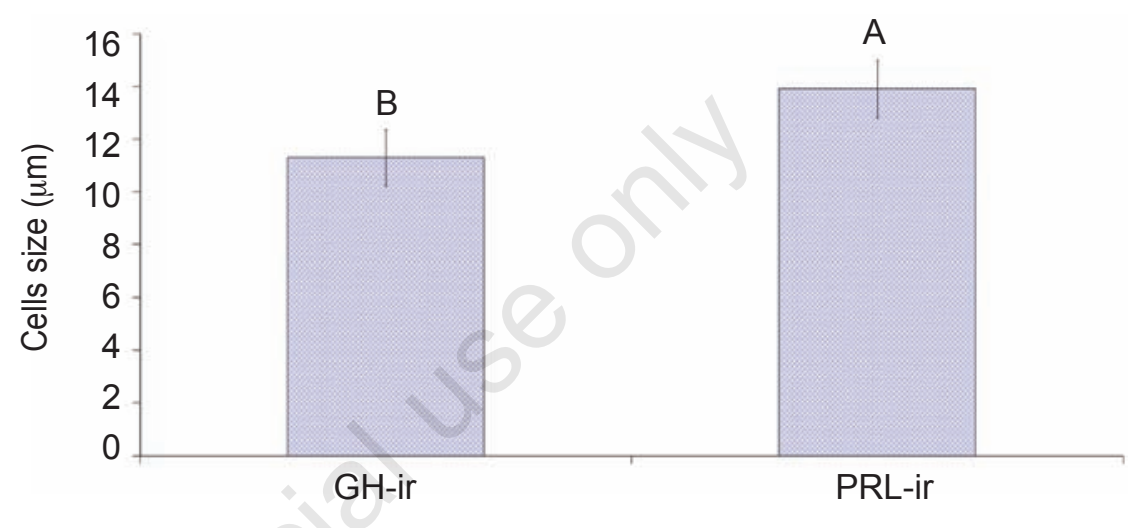

Figure 4. Overall mean immunoreactive somatotroph and lactotroph cell size $(\mu \mathrm{m} \pm \mathrm{SE})$ before and at different stages of zinc induced moult. GH-ir: immunoreactive growth hormone producing cells. PRL-ir: immunoreactive prolactin producing cells. $\mathrm{AB}=$ differ significantly at $\mathbf{P} \leq \mathbf{0 . 0 5}$.

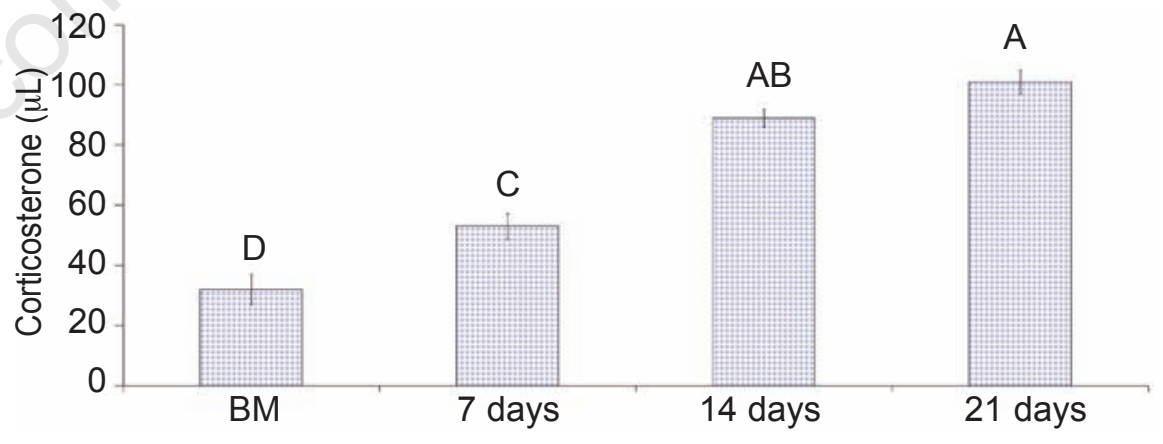

Figure 5. Mean serum corticosterone concentrations $(\mathrm{ng} / \mathrm{mL})$ of moulting hens before and during the induced moulting of laying hens. $A-D=$ do not differ significantly at $\mathbf{P} \leq 0.05$.

in the center of caudal zone, but on the margins ir-GH cells were abundant. Ir-GH cells were found only in the caudal lobe with a few cells at an area intermediate to the caudal and cephalic lobes. PRL-ir cells were observed polymorph in shape. Some cells were polygonal and others were ovoid with cytoplasmic extension as shown in Figure 1-A; hypertrophied cells were also observed (Figure 1-B). It was also found that this change in shape and morphology of nucleus was present in all ir-PRL cells at all physiological stages of moulting. GH-ir cells at different stages of moulting phases were ovalto-round shaped and were discrete in the caudal lobe of adenohypophysis. No ir-GH cells were observed in the cephalic lobe of chicken 
pituitary gland. PRL-ir cells were present in clusters and very few isolated cells, but ir-GH cells were mostly isolated to each other with very few cells in a cluster formation (Figure 1C). The negative tissue control was processed at the same time with no observable immunostaining (Figure 1-D). The largest numbers of irPRL cells were observed at BM. After 7 days of Zn0 supplementation (moulting period) the population of ir-PRL cells remained significantly more than ir-GH cells. Both types of cell populations decreased further and remained nonsignificant after 14 and 21 days of treatment (Figure 2). However, ir-GH population remained non-significantly different during the period of induced moulting. Overall mean immunoreactive cell numbers were significantly high at BM and then decreased afterwards during the period of induced moulting (Figure 3). Overall mean ir-PRL cell size increased significantly compared to ir-GH cells during the moulting phase (Figure 4), but serum corticosterone concentration was significantly higher at the end of moulting (21 days) phase. There was a significant increase in serum corticosterone concentration with the passage of time of the moulting phase / time of laying hens (Figure 5). Overall serum corticosterone concentration remained higher than before the moulting phase.

\section{Discussion}

In this study we have successfully identified the extent of moulting influence on the relative proportions of somatotrophs and lactotrophs over the moulting phase of laying hens. Furthermore, we determined the ontogenic profile of these cells, as quantitative and morphological descriptions are scant. Our study demonstrates the presence and distribution of ir-PRL and ir-GH cells in moulting hens as they had already been described in the hyperprolactinemia stage of turkies anterior pituitary glands. ${ }^{1}$ In the present study, we used immunohistochemistry to identify ir-PRL and ir-GH cells in the pituitary gland of moulting hens and for their quantitative enumeration. It has already been reported that ir-PRL cells are present in the central and dorso-caudal zones of pars distalis and that these cells population increase during the periods of pregnancy and lactation; however, they showed a sparse distribution in the central zone of pars distalis in bats during hibernation. ${ }^{12}$ Ir-PRL cells are found only in the cephalic zone, while ir-GH cells are predominantly found in the caudal lobe in the laying hen's pituitary gland as reported by Ramesh et al. ${ }^{13}$ for turkey hens; notwithstanding, during this study we also found ir-PRL in the caudal lobe of moulting hens. Our results are in line with the findings of Barabanov et al. ${ }^{14}$ and Kansaku et al. ${ }^{15}$, who reported that ir-PRL cells are present in both zones of hens pars distalis. Our results are also strengthened by the findings of Kansaku et $a l .{ }^{15}$ demonstrating that prolactin mRNA is present in both cephalic and caudal lobes of hypophysis in domestic cocks. Similar findings were also reported by Erdost. ${ }^{16}$ The increase in ir-PRL cells during the moulting phase may be due to the conversion of ir-GH cells into mammosomatotrophs and started secreting PRL for the its increased need during the phase of hyperprolactinemia in the resting phase of hen. ${ }^{1}$ Hoeffler et al. ${ }^{17}$ concluded that almost all of the initial PRL cells in rats are mammosomatotrophs. In mammals, lactotrophs arise from somatotrophs or a common precursor cell type during development. For instance, in rats the appearance of ir-PRL occurs around birth and approximately one week after $\mathrm{GH}$ cell differentiation. ${ }^{18}$ In our study there was an increase in immunoreactive cell numbers at the start of moulting, which decreased further with the passage of time. In our opinion, the decrease in ir-PRL cell numbers in the process of induced moult may be due to the effects of decreasing light in the moulting period. Another explanation for the cell numbers decrease after 7 days of moulting may be due to the apoptosis process. ${ }^{19}$ In our study ir-PRL cell size increased compared to ir-GH cells during the period of induced moulting and then decreased towards the end of induced molting. To date, most evidence has favoured the hypothesis that the age-associated hyper-prolactinemia results primarily from alternation in the hypothalamus and/or other parts of the central nervous system. Likewise, prolactin stimulates lactation in the post-partum period of mammalians. Hyperprolactinemia is a normal physiological mechanism that develops at the end of the production cycle in avian species and during lactation in mammals. The presence of hypertrophied cells may be due to an increased need for prolactin at the end of the production cycle.

In chicken, the temporary increase of plasma corticosterone during feed restriction probably stimulates glucose output from the liver, moving towards hypoglycemia until glucose production from fat catabolism is established. ${ }^{20}$ Glucocorticoids usually suppress human and rat PRL gene expression and can inhibit lactotroph differentiation, while increasing $\mathrm{GH}$ expression and somatotroph differentiation in rats during early days of embryonic life. ${ }^{21}$ However, Fu et al. ${ }^{18}$ reported the increased effect of corticosterones on the proliferative activity of lactotrophs and somatotrophs. The logical possibility of contradiction among these two studies and our investigation may be the dose related response of corticosterones towards lactotrophs and different physiological stages e.g. developmental and moulting phase of laying hens.

To our knowledge this is the first study in which the effects of induced moulting on pituitary somatotrophs and lactotrophs in laying hens have been assessed. We have demonstrated that induced moulting decreases the proportion of lactotrophs without any prominent effects on somatotroph proportion, suggesting that corticosterone may have suppressed the prolactin gene transcription.

\section{References}

1. Ramesh R, Solow R, Proudman JA, Kuenzel WJ. Identification of mammosomatotrophs in the turkey hen pituitary: increased abundance during hyperprolactinemia. Endocrinology 1998;139:781-6.

2. Pasolli HA, Torres AI, Aoki A. The mammosomatotroph: a transitional cell between growth hormone and prolactin producing cells? An immunocytochemical study. Histochemistry 1994;102:287-96.

3. Yilmaz B. Physiology of hormones and reproductive system, Feryal Press, Ankara. 38-45, 1999.

4. Dellmann HD, Eurell A. Textbook of Veterinary Histology. Fifth Edition, Williams \& Wilkins, USA, 1998.

5. Proudman JA, Vandesande F, Berghman LR. Immunohistochemical evidence that follicle-stimulating hormone and luteinizing hormone reside in separate cells in the chicken pituitary. Biol Reprod 1999;60: 1324-8.

6. al-Batshan HA, Scheideler SE, Black BL, Garlich JD, Anderson KE. Duodenal calcium uptake, femur ash, and eggshell quality decline with age and increase following moult. Poult Sci 1994;73:1590-6.

7. Dickerman RW, Wise TH, Bahr JM. Effect of ovarian regression and moult on plasma concentrations of thymosin beta 4 in domestic hens (Gallus domesticus). Domest Anim Endocrinol 1992;9:297-304.

8. Dickerman RW, Bahr JM. Moult induced by gonadotropin-releasing hormone agonist as a model for studying endocrine mechanism of moulting in laying hens. Poult Sci 1989;68:1402-8.

9. Porter TE, Lopez ME, Mike R, Huberty AF. The increase in prolactin-secreting cells in incubating chicken hens can be mimicked by extended treatment of pituitary cells in vitro with vasoactive intestinal polypeptide (VIP). Domest Anim Endocrinol 2006;30: 126-34

10 Sandhu MA, Rahman ZU, Rahman SU. Dynamics of macrophages in laying hens 
during second and third production cycles after zinc induced moulting. J Poult Sci 2006;43:286-95.

11. SAS. Procedures Guide, Version 6, 3rd Ed., 1995, SAS Institute, Cary, NC, USA.

12. Mikami S, Chiba S, Hojo H, Taniguchi K, Kubokawa K, Ishii S. Immunocytochemical studies on the pituitary pars distalis of the Japanese long-fingered bat, Miniopterus schreibersii fulinginosus. Cell Tissue Res 1988;251:291-9.

13. Ramesh R, Proudman JA, Kuenzel WJ. Changes in pituitary somatotroph and lactotroph distribution in laying and incubating turkey hen pituitary. Gen Comp Endocrinol 1996;104:67-75.

14. Barabanov VM. Immunohistochemical detection of prolactin in the hypophysis of the chick and chick embryo. Ontogenez 1985;16:118-26.

15. Kansaku N, Shimada K, Saito N. Regionalized gene expression of prolactin and growth hormone in the chicken anterior pituitary gland. Gen Comp Endocrinol 1995;99:60-8.

16. Erdost H. Immunohistochemical distribution of prolactin containing cells in the pituitary of the chickens. Vet Med - Czech 2005;50:225-9.

17. Hoeffler JP, Boockfor FR, Frawley LS. Ontogeny of prolactin cells in neonatal rats: initial prolactin secretors also release growth hormone. Endocrinology 1985;117: 187-95.

18. Fu X, Nishimura S, Porter TE. Evidence that lactotrophs do not differentiate direct- ly from somatotrophs during chick embryonic development. J Endocrinol 2004;183: 417-25.

19. Yoshimura Y, Heryanto B, Tamura T. Changes in the population of proliferating cells in chicken anterior pituitary during induced moulting: an immunocytochemical analysis for proliferating cell nuclear antigen. Poult Sci 1997;76:1569-73.

20. Webster AB. Physiology and behavior of the hen during induced moult. Poult Sci 2003;82:992-1002.

21. Sato K, Watanabe YG. Corticosteroids stimulate the differentiation of growth hormone cells but suppress that of prolactin cells in the fetal rat pituitary. Arch Histol Cytol 1998;61:75-81. 